\title{
Subjektivitas Dalam Iklan Ambient Media Miracle Aesthetic Clinic
}

\author{
Wegig Murwonugroho \\ FSRD Universitas Trisakti, dan \\ Yasraf Amir Pilliang \\ FSRD Institut Teknologi Bandung
}

\begin{abstract}
Subjectivity in advertisement is a 'power' possessed by advertisements to construct trend, concept, truth, Subjectivity in the advertisement is the power that possessed by an advertisement to construct trend, truth, to ideology that happens through unconsciousness. Advertisement functions as a message-carrier which visually represents something through metaphors that bridging between imaginative image and reality. Ambient media is an advertisement media that utilizes the environment where the advertisement is located. Miracle Aesthetic Clinic (Miracle) visually represented its ambient media by omitting the both faces of the female mannequins. The face of an advertisement model is an image commodity that generally has commercial values, yet in both of these advertisements; the faces were drowned into the base of a table and a wall. This research uses critical analysis discourse research method to analyze the subjectivity in the interpretation of ambient media. Advertisement subjectivity in "Miracle" commercial that violateloffence women cannot occur, being eliminated, as becoming a horrible figure in the social culture to have a face with acnes. This Miracle ambient media commercial succeeds in constructing a new trend of interpretation of beauty that is not restricted only in its common benchmark characteristics of beauty.
\end{abstract}

Keywords: Ambient media, subjectivity, power, women ideal beauty.

\begin{abstract}
ABSTRAK
Subjektivitas di dalam iklan adalah kuasa yang dimiliki iklan untuk mengkonstruksi trend, kebenaran, hingga ideologi yang terjadi melalui alam bawah sadar. Iklan berfungsi menyampaikan pesan, yang direpresentasi-visualkan melalui metafora-metafora yang menjembatani antara gambaran imajinasi dan realitas. Ambient media merupakan media beriklan yang memanfaatkan lingkungan di mana iklan ditempatkan. Miracle Aesthetic Clinic (Miracle) merepresentasi-visualkan iklan ambient media-nya dengan cara menghilangkan tampilan wajah kedua boneka perempuan. Wajah model iklan merupakan komoditi pencitraan yang pada umumnya memiliki nilai jual, namun dalam kedua iklan ini justeru ditenggelamkan ke dalam alas meja dan dinding tembok. Penelitian ini menggunakan metode penelitian Analisa Wacana Kritis untuk menganalisa subjektivitas di dalam pemaknaan ambient media. Subjektivitas iklan Miracle menyudutkan perempuan tidak dapat hadir, tersisih, menjadi sosok yang mengerikan di dalam tataran sosialnya ketika wajah berjerawat. Iklan ambient media Miracle ini berhasil mengkonstruksi wacana trend baru kecantikan wajah yang tidak terbatas pada tolok ukur karakteristik kecantikan pada umumnya.
\end{abstract}

Kata kunci: ambient media, subjektivitas, kuasa, kecantikan ideal perempuan. 


\section{PENDAHULUAN}

Iklan kecantikan menjadi tanda yang menandai citra feminitas perempuan. Berbagai konsep iklan kecantikan memiliki kecenderungan tidak hanya sebatas menyampaikan pesan komersial, tetapi juga menanamkan ideologi kekinian akan konsep 'kecantikan wajah dan tubuh perempuan'. Iklan menjadi subjek yang memiliki identitas dan menjembatani antara dunia imajiner dan realitas. Foucault mengemukakan bahwa:

"The subject is understood by Foucault not as something simple, merely a conscious doer, but as something that must be constructed. This is correlative to his focus on practices and techniques: since these things vary historically, so too does subjectivity itself." (Kelley, 2000:513-515)

Subjek tidak sebagai sesuatu yang sederhana, hanya sekedar pelaku yang sadar, tetapi sebagai sesuatu yang harus dikonstruksi. Lebih lanjut Foucault mengemukakan bahwa: "Subjectivity to be something constituted, and specifically something historically constituted." Subjektivitas sebagai sesuatu yang 'dibentuk' dan khususnya sesuatu yang dibentuk melalui tataran sejarah; pengalaman, kehidupan sosial, dan mitos termasuk di dalamnya.

Subjektivitas iklan diwujudkan dengan kemampuannya untuk mengkonstruksi, mengkontrol, dan membangun kesadaran diri khalayak yang mengkonsumsinya. Iklan menyuguhkan imajinasi kesempurnaan wajah dan tubuh perempuan ke dalam realitas melalui representasi visual. Representasi visual tubuh dan wajah perempuan hadir dalam berbagai bentuk metafora. Metafora adalah pemanfaatan unsur-unsur visual sebagai pengalihan objek dan situasi yang dikomposisikan hingga memunculkan pemaknaan baru. Istilah lain dari metafora adalah kiasan.

Ambient media merupakan media beriklan yang memanfaatkan unsur-unsur lingkungan di mana iklan ditempatkan. Media beriklan ini dipilih Saatchi \& Saatchi Indonesia (Saatchi) -sebagai kreator iklan untuk mempromosikan produk perawatan kecantikan wajah Miracle Aesthetic Clinic (Miracle). Figure of speech (cara bertutur atau majas) iklan ambient media dengan cara penghilangan representasi visual wajah. Gagasan utama penenggelaman wajah membedakan dengan narasi iklan-iklan produk perawatan kecantikan yang pada umumnya menampilkan keunggulan wajah dan tubuh modelnya. Wajah tidak lagi menjadi komoditas utama yang dijual.

Foucault menjelaskan kehadiran tubuh, erat kaitannya dalam pembentukan subjektivitas. Tampilan model iklan berwajah cantik dengan tubuh yang ideal memiliki peran kuat di dalam pembentukan subjektivitas iklan. Dengan demikian ada kecenderungan iklan akan kehilangan subjektivitasnya ketika iklan hadir tanpa tampilan visual wajah. Tujuan penelitian ini adalah diketemukannya paparan subjektivitas dan pemaknaan yang dipahami konsumen melalui ketidakhadiran representasi visual wajah pada ambient media Miracle Aesthetic Clinic. Bagaimanakah pemaknaan tekstual representasi visual ambient media? Bagaimanakah peran ambient media sebagai media diskursus? Bagaimanakah wacana sosial budaya mengkonstruksi pemaknaan iklan dalam praktek sosial?

\section{Subjektivitas, Tubuh, dan Identitas}

Subjektivitas adalah suatu pengalaman, dan terbuka untuk ketidakkonsistenan, kontradiksi, dan kesadaran-bukan diri. Sedangkan, menurut Foucault, sub- 
jektivitas dibentuk oleh sistem dominan dari organisasi sosial yang bertujuan mengatur manusia. Subjektivitas adalah kesadaran diri sebagai subjek yang terpisah dari subjek lainnya, dengan kemampuan untuk berperilaku. Subjektivitas juga mencakup 'a sense of being subject to, under the control of something external to ourself...' Suatu kesadaran menjadi dominasi, di bawah pengawasan sesuatu di luar dirinya. Yang dimaksud dengan sesuatu di luar dirinya adalah kondisi lingkungan sosial dan budaya termasuk di dalamnya berbagai wacana yang muncul. (Giles dan Middleton, 1999:211 dalam Ayuningtyas, 2009:12 )

Ayuningtyas mengatakan bahwa subjektivitas dan tubuh tidak dapat dipisahkan.

The body for Foucault is more than the locus of subjectivity; it is the very condition of subjectivity. For Foucault, consciousness and subjectivity are not separable from the body... Foucault's view that the body is not simply given but is culturally constructed. (2009:11)

Tubuh lebih dari sekedar tempat keberadaan subjektivitas; tubuh merupakan subjektivitas itu sendiri, karena kesadaran dan subjektivitas tidak dapat dipisahkan dari tubuh, dan tubuh tidak hadir apa adanya, namun dikonstruksi oleh sosial budaya. Model iklan yang identik dengan 'tubuh perempuan' berfungsi sebagai medium untuk merefleksikan 'subjektivitas' manusia. Tubuh berfungsi sebagai medium untuk merefleksikan subjektivitas manusia, dan pengolahan tubuh manusia merupakan kegiatan yang dilakukan manusia untuk membentuk identitas diri. Mengacu pada penjelasan Foucault, tubuh merupakan medium pembentukan subjektivitas dan identitas.
Pengolahan model iklan di dalam ambient media Miracle sebagai bentuk representasi tubuh manusia merupakan kegiatan yang dilakukan pengiklan untuk membentuk 'identitas'. Identitas itu sendiri dipengaruhi oleh inter subjektivitas dan interaksi sosial budaya. Identitas juga berkaitan dengan konsep representasi, seperti dijelaskan oleh Hall bahwa identitas adalah perkara merepresentasikan diri. Iklan berfungsi sebagai penentu trend, di mana khalayak sasaran akan merepresentasi dirinya identik dengan iklan tersebut. Iklan-iklan kini telah mengkonstruksi representasi subjektivitas seseorang (Ayuningtyas, 2009:11).

Identitas adalah suatu entitas yang dapat diubah-ubah menurut sejarah, waktu dan ruang tertentu. Identitas bersifat sosial. Tubuh sebagai model iklan disusun menjadi individu (subjek) melalui proses sosial. Proses itu terjadi dalam diskursus bahasa yang memungkinkan melalukan interaksi dengan yang lain. Dengan demikian, subjektivitas merujuk pada kondisi proses bagaimana seseorang menjadi individu, dan bagaimana ia dikonstitusi sebagai subjek, sehingga identitas adalah hasil konstruksi sosial dan senantiasa ada di dalam berbagai bentuk representasi sosial. (Evi Fadillawati, 2011:5-6).

\section{Iklan sebagai Medium Pembentuk Feminitas}

Iklan adalah salah satu produk budaya populer yang berfungsi tidak hanya sebagai medium untuk menyampaikan pesan, akan tetapi juga sebagai medium pembentuk feminitas. Pada umumnya iklan kecantikan mengkonstruksi ideologi 'cantik' dengan model perempuan berpostur tinggi, langsing, berkulit bersih tanpa jerawat, rambut yang tertata, dan berdandan dengan mode terkini, serta pemilihan jenis alas kaki yang meno- 
pang sehingga tungkai terlihat lebih tinggi. Ideologi ini direpresentasi-visualkan dengan penambahan teknis pengolahan imej sehingga wajah terlihat lebih putih, bersih dari noda, tanpa pori-pori, kerut wajah tidak nampak, dan pendistorsian olah digital membentuk imej tubuh terlihat lebih langsing dari bentuk real-nya, dada lebih besar, dan pinggul lebih kecil. Ketika berada di alam bawah sadar perempuan akan terdorong mengkonsumsi produk atau jasa perawatan kecantikan tersebut untuk memiliki penampilan cantik yang 'identik' dengan imej pada model iklan. Identitas dirinya disetarakan dengan identitas imej yang ada pada iklan.

\section{Iklan Kecantikan sebagai Produk Budaya Populer}

Budaya populer adalah kekuatan dinamis yang menggeser batasan kuno, tradisi, selera, dan mengaburkan segala bentuk perbedaan. Budaya pop merupakan budaya komersial yang diproduksi massal untuk dikonsumsi secara massal. Budaya massa mencampuradukkan segala sesuatu dan menghasilkan apa yang disebut homogenitas. Ray B. Browne dalam Mass Media Mass Culture, 1995, mendefinisikan budaya populer sebagai budaya setiap orang dalam masyarakat, sebuah budaya dunia yang mengelilingi kita; meliputi sikap, kebiasaan, dan perilaku (Inda Fitryarini, 2009:130-131). Sedangkan, McQuail dalam Mass Communication (1983:287) mengatakan bahwa budaya populer memiliki ciri keaslian yang bersifat spontan dan keberadaannya berlangsung terus menerus dalam kehidupan sosial dengan bentuk yang beraneka ragam. (Inda Fitryarini, 2009:131). Budaya populer terhubung erat dengan masyarakat sebagai sasaran media karena masyarakat akan terus menciptakan budaya popular (Fitryarini, 2009: 131).
Budaya populer menjadi sebuah tren ketika ia memiliki keseragaman bentuk, mudah dinikmati dan diadaptasi oleh masyarakat, mampu memiliki daya tahan dan keunikan untuk tetap memenangkan persaingan dan memiliki keuntungan ekonomis. Budaya populer dan ekonomi tidak terpisahkan. Budaya populer identik dengan istilah 'trend', maka nilai komersial adalah kendaraan yang digunakan budaya populer untuk menjadi besar (Inda Fitryarini, 2009: 131-132).

\section{METODE}

Penelitian kualitatif ini meng-gunakan metode Analisis Wacana Kritis (Critical Discourse Analysis) merupakan penelitian empiris yang mencari hubungan antara wacana dengan perkembangan sosial budaya. Terdapat tiga analisis di dalam Analisis Wacana Kritis, yaitu: 1). Analisis tekstual; 2). Analisis praktek diskursus; dan 3). Analisis praktek sosial.

Analisis tekstual menganalisis iklan ambient media (bahasa visual) sebagai sebuah teks. Akar dari Analisis Wacana Kritis adalah retorika klasik, linguistik sosial, teks linguistik, linguistik terapan, dan pragmatik. Analisis praktek diskursus merupakan kajian bagaimana tanda diproduksi dan bagaimana tanda dikonsumsi. Adapun pada analisis praktek sosial, menganalisis praktek budaya sosial yang mempengaruhi pemaknaan teks. Analisis ini berfokus pada cara dominasi politik dan sosial yang direproduksi dalam teks dan tuturan. Gagasan mengenai ideologi, kekuatan, hirarki, jender, dan variabel sosial dipahami memiliki keterkaitan terhadap pemaknaan atau interpretasi teks.

Ide dasar terciptanya sebuah iklan tentunya didasari oleh konsep 'wacana' apa yang akan dinarasikan. Kehadiran iklan di tengah publik juga akan memunculkan 
pemaknaan yang banyak dipengaruhi oleh 'wacana' sosial budaya. Terdapat 4 (empat) unsur yang dikaji, yaitu: pelibat, medan, relasi, dan interaksi. Bagaimana para pelibat (iklan, khalayak sasaran, dan lingkungan fisik maupun sosial) memainkan perannya sebagai aktor, berikut kuasanya di dalam berelasi dalam sebuah medan. Medan merupakan lingkungan fisik berikut pergerakan khalayak sasaran di mana iklan ditempatkan. Lebih lanjut terjadi interaksi di antara pelibat. Interaksi terhadap ambient media ini memunculkan berbagai pemaknaan yang diawali dengan persepsi, interpretasi, hingga munculnya respon. Pemaknaan khalayak sasaran ini dipengaruhi oleh berbagai wacana.

\section{HASIL DAN PEMBAHASAN}

Pembahasan pemaknaan iklan ambient media ini tersusun dalam tiga pembahasan. 1). Analisis Tekstual, 2). Analisis Praktek Diskursus, dan 3). Analisis Praktek Sosial.

\section{Analisis Tekstual}

Ambient media Miracle terdiri atas boneka perempuan yang tereltelungkup di meja dan menatap dinding. Ambient media yang tertelungkup di atas meja ini merepresentasikan identitas seorang pengunjung Adorama Photo yang tertelungkup di meja. Pada ambient media disematkan atribut: rambut palsu warna hitam, lurus, berkilau dan panjang, kemeja blaser hijau lengan panjang, rok panjang biru muda, syal berwarna oranye tua, sepatu boot dengan hak tinggi untuk membentuk identitas seorang pengunjung yang bergaya casual. Atribut tersebut memberikan kesan nyata (real) pada tubuh ambient media. Boneka yang seakan menjadi tubuh manusia yang hidup meng-konstruksi sebuah konsep subjektivitas yang malu tidak mau menatap publik. Khalayak sasaran tidak memiliki kuasa untuk menyentuh ambient media karena mereka masih ragu-ragu apakah ambient media adalah tubuh yang nyata atau palsu.

Peneliti mengkompilasi berbagai pemaknaan dari para responden yang terlibat sebagai pelibat (khalayak sasaran).

Di dalam buku Interpretation, sebuah teks memiliki kemandirian totalitas yang bercirikan tidak terikat dengan khalayak, tidak terikat dengan sistem dialog, makna teks tidak terikat pada pembicara dan terlepas dari pengungkapan (what is said). Teks melahirkan definisi interpretasi dan eksplanasi, di mana interpretasi adalah cara kerja dari teks ke metafor dan eksplanasi adalah cara kerja yang menghubungkan metafor ke teks. Antara interpretasi dan eksplanasi tidak dapat dipisahkan karena eksplanasi adalah sebagai tahap awal untuk mengkaji statis teks, sementara interpretasi digunakan untuk menangkap makna kontekstual dari teks tersebut (Paul Ricoeur, 2014:219).

Tanda sebagai unit terkecil komunikasi dalam sistem bahasa. Setiap tanda terdiri atas penanda dan petanda. Kata, bahasa tubuh, gambar, suara, foto, film, dan termasuk iklan ambient media, memungkinkan untuk diteliti menggunakan semiotika. Hubungan antara penanda dan petanda adalah tidak terpisahkan dan bersifat mana suka (arbitrer) dalam menciptakan makna. Penanda adalah bentuk fisik dari tanda dan petanda adalah konsep mental yang diacu oleh penanda (Turner, 1996:15).

Penayangan konsep iklan kecantikan tubuh perempuan yang dilakukan terus menerus menjadi suatu kebenaran umum dan menimbulkan kecemasan bagi perempuan yang tubuhnya tidak memiliki karakteristik 'feminitas ideal' yang digaungkan oleh iklan produk kecantikan. Seringkali iklan direpresentasikan dengan 


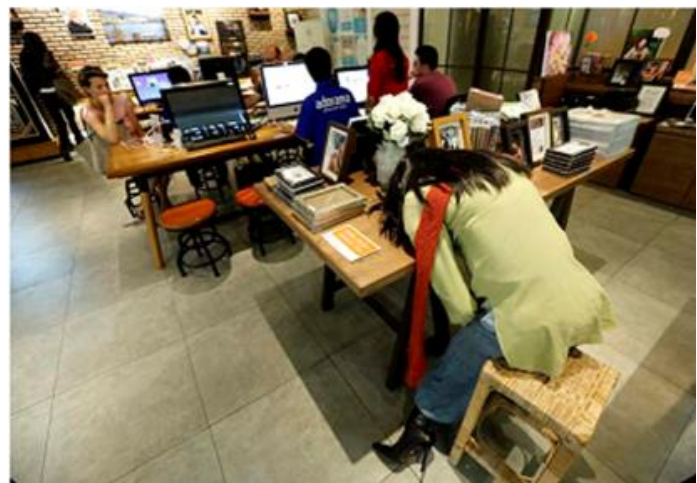

Gambar 1.

Iklan Ambient Media Faceless Miracle

Aesthetic Clinic. Perempuan Tertelungkup di Meja. Sumber: Wegig Murwonugroho, 2013

konsep oposisi biner: baik-buruk, putihgelap, cantik, jelek. Jelek identik dengan berjerawat, gemuk, pendek, berkulit gelap, keriting. Kepemilikan perwujudan tubuh dengan karakteristik 'jelek' dianggap sebagai 'liyan' yang tubuhnya harus dikonstruksi ulang melalui pengkonsumsian produk-produk kecantikan yang ditawarkan oleh iklan. Representasi visual tubuh dan wajah perempuan yang dibenamkan pada ambient media mengkonstruksi subjektivitas bahwa seorang perempuan telah 'kehilangan identitas kefeminitasnya' dengan penampilan konsep oposisi biner yang ditakuti perempuan sebagai perempuan yang tersisih, tidak berani tampil di hadapan publik.

\section{Analisis Praktek Diskursus: Iklan sebagai Media Pengiring Alam Bawah Sadar}

Pesan persuasif iklan ambient media Miracle memiliki potensi kemampuan untuk membangkitkan dan melumpuhkan kesadaran massa dalam jangka waktu yang tidak bisa ditentukan. Meminjam istilah Cultivation Theory oleh George Gerbner, iklan produk kecantikan menancapkan ide kebenaran di benak khalayak bahwa iklaniklan produk kecantikan hadir karena dibutuhkan dan penting bagi khalayak. Dan mereka yang tidak mengenal atau menyukai produk-produk kecantikan yang ditampilkan dalam iklan dianggap sebagai

Tabel 1: Analisis Iklan Ambient Media Faceless Miracle Aesthetic Clinic Ambient, Perempuan Tertelungkup di Meja

\begin{tabular}{|c|c|c|}
\hline Unsur & Penanda & Petanda \\
\hline Tubuh & $\begin{array}{l}\text { Boneka perempuan bertubuh } \\
\text { langsing tidak terlihat } \\
\text { ketinggiannya karena dalam } \\
\text { posisi duduk. }\end{array}$ & $\begin{array}{l}\text { Menunjukkan jender perempuan, } \\
\text { feminim. }\end{array}$ \\
\hline Atribut pakaian dan aksesoris & Mengenakan blaser hijau, tas & Mengindikasikan pengunjung \\
\hline yang dikenakan & $\begin{array}{l}\text { kulit, syal oranye, rok panjang } \\
\text { biru muda, dan beraroma wangi. }\end{array}$ & $\begin{array}{l}\text { Adorama. Suka berdandan } \\
\text { (fashionable), mengikuti } \\
\text { pergerakan mode dan berkelas. }\end{array}$ \\
\hline Rambut & $\begin{array}{l}\text { Lurus hitam terurai menutup } \\
\text { wajah. }\end{array}$ & $\begin{array}{l}\text { Perempuan yang menjaga } \\
\text { penampilan. }\end{array}$ \\
\hline Gerakan tubuh & Duduk dan membungkuk & Gerakan yang tidak lazim. \\
\hline Posisi wajah & Dibenamkan ke alas meja & Malu, sedih, stress, galau. \\
\hline $\begin{array}{l}\text { Lingkungan di mana ambient } \\
\text { media ditempatkan }\end{array}$ & $\begin{array}{l}\text { Boneka ditempatkan di dalam } \\
\text { ruangan editing seluas } 6 \times 15 \mathrm{~m}^{2} \\
\text { dengan cahaya lampu terang. }\end{array}$ & $\begin{array}{l}\text { Memunculkan suasana } \\
\text { penasaran. }\end{array}$ \\
\hline Caption & $\begin{array}{l}\text { Can't face the world. Mirade } \\
\text { Aesthetic Clinic. }\end{array}$ & $\begin{array}{l}\text { Tanda ini tidak banyak dibaca. } \\
\text { Namun ad a yang dapat } \\
\text { memaknai 'malu untuk } \\
\text { menampilkan dirinya' }\end{array}$ \\
\hline
\end{tabular}


orang yang konvensional (Fitryarini, 2009: 126-127). Iklan produk kecantikan memberikan pesan bahwa hal terpenting dalam diri perempuan adalah kepemilikan feminitas ideal yaitu tubuh dan wajah yang cantik untuk memikat perhatian orang lain. Pesan-pesan iklan produk kecantikan yang bersifat sugestif dan di bawah kesadaran, sehingga mampu mengaktifkan dorongandorongan bawah sadar yang mendominasi kehidupan manusia, yaitu selalu tertarik dan menarik orang lain melalui penam-pilan fisik cantik. Bagi Foucault, sub-jektivitas merupakan produksi diskursif, di mana diskursus (sebagai cara yang diregulasikan atas speaking atau practice) memungkinkan orang untuk bicara atau praktik pada posisi subjek, pada hal-hal yang dapat menyubjekkan orang tersebut sebagai pembicara atau praktisi (yang memproduksi atau mereproduksikan kembali diskursus tersebut) (Rizma, 2014:6)

Ide binary opposition dalam kreatif periklan jasa kecantikan menjadi tema populer iklan kosmetik. Perlawanan biner diwujudkan dalam tampilan buruk rupa, ranah domestik, tanpa kekuatan, 'dipertentangkan' dengan wajah cantik, mampu memiliki peran ranah publik, dan memiliki aura. Seseorang yang bertubuh dan berwajah tidak ideal ditampilkan dengan

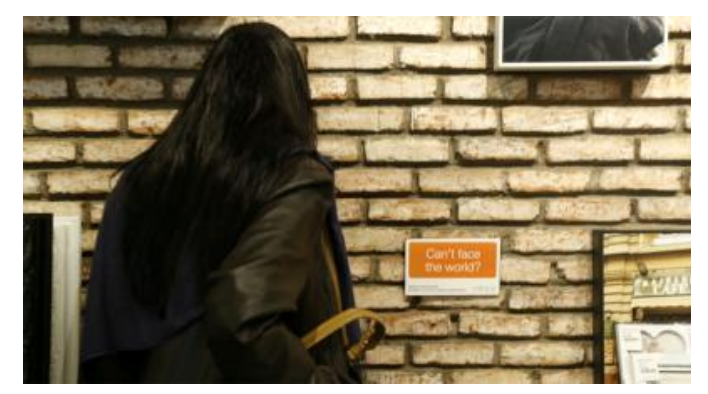

Gambar 2.

Iklan Ambient Media Faceless Miracle Aesthetic Clinic. Perempuan

Menyembunyikan Wajah di Dinding.

Sumber: Wegig Murwonugroho, 2013 menundukkan wajah dan menempati sedikit ranah publik, sedangkan seseorang yang memiliki wajah dan tubuh ideal, di dalam iklan, akan digambarkan sebagai wanita yang penuh percaya diri dan menempati lebih banyak ruang publik. Perempuan dikonstruksi menjadi perempuan yang merasa tidak percaya diri jika tidak memiliki kemampuan mengkontrol wajah dan tubuhnya. Make up menjadi dialog pribadi yang secara tidak sadar dihadapkan tiap pagi sebelum mengawali aktifitas. Identitas apa yang akan dihadirkan hari ini.

Dapat dipahami bahwa untuk mendapatkan identitasnya, tubuh perempuan harus selalu dikontrol melalui agen pendisplin tubuh yaitu: pusat perawatan wajah. Disiplinitas tubuh bersifat paradok-sikal. Di satu sisi menjadikan wajah dan tubuh wanita sebagai objek yang selalu ada ketergantungan, selalu dikontrol. Foucault menyebutnya sebagai docile body, tubuh yang bersedia untuk ditindas oleh berbagai macam praktek kecantikan guna mendapatkan representasi cantik pada tubuh dan wajahnya. Di lain sisi, kesediaan wanita untuk mendisiplinkan tubuhnya melalui berbagai macam praktek kecantikan yang menindas akan memberikan wanita subjektivitas pada identitas jendernya. Seperti yang dijelaskan oleh Stephanie Genz (2009) bahwa pengoptimalan feminitas pada tubuh akan menjadikan subjektivitas perempuan menunjukkan eksistensi peran jendernya.

\section{Analisis Praktek Diskursus: Relasi di Antara Pelibat}

Dieter Heinrich menjelaskan bahwa intersubjektivitas terjadi jika diri masingmasing subjek berinteraksi satu dengan yang lain di dalam suatu komunikasi. Penayangan iklan-iklan merupakan rekonstruksi ulang agar dapat merekam respon khalayaknya. Khalayak sasaran sengaja dihadirkan dalam 'satu medan' (ruang dan waktu 
Tabel 2: Penanda dan petanda dari Ambient Media berdiri di Adorama Kemang

\begin{tabular}{|c|c|c|}
\hline Unsur & Penanda & Petanda \\
\hline Tubuh & $\begin{array}{l}\text { Boneka perempuan bertubuh } \\
\text { langsing dan terlihat sangat } \\
\text { menjaga berat badannya. }\end{array}$ & $\begin{array}{l}\text { Memvisualisasikan jenis kelamin } \\
\text { perempuan yang feminim. }\end{array}$ \\
\hline $\begin{array}{l}\text { Atribut pakaian dan aksesoris } \\
\text { yang dikenakan }\end{array}$ & $\begin{array}{l}\text { Mengenakan jaket hitam, tas } \\
\text { kulit, celana jeans, dan beraroma } \\
\text { wangi. }\end{array}$ & $\begin{array}{l}\text { Penampilan yang sangat } \\
\text { fashionable dan mengikuti trend } \\
\text { mode masa kini. Tipikal } \\
\text { pengunjung Adorama Photo. }\end{array}$ \\
\hline Rambut & $\begin{array}{l}\text { Berwarna hitam, lurus terurai, } \\
\text { dan menutupi seluruh wajah. }\end{array}$ & $\begin{array}{l}\text { Ciri-ciri perempuan yang } \\
\text { menjaga penampilan fisiknya. }\end{array}$ \\
\hline Gerakan tubuh & Berdiri condong ke dinding & Perilaku yang tidak biasa. \\
\hline Posisi wajah & $\begin{array}{l}\text { Disembunyikan ke dalam } \\
\text { dinding }\end{array}$ & $\begin{array}{l}\text { Tidak percaya diri, malu, sedih, } \\
\text { dan stress. }\end{array}$ \\
\hline $\begin{array}{l}\text { Lingkungan di mana ambient } \\
\text { media ditempatkan }\end{array}$ & $\begin{array}{l}\text { Mannequin perempuan } \\
\text { ditempatkan di ruang editing } \\
\text { Adorama Photo seluas } 6 \times 15 \mathrm{~m}^{2} \\
\text { dengan penerangan yang baik. }\end{array}$ & $\begin{array}{l}\text { Memunculkan suasana } \\
\text { menakutkan. }\end{array}$ \\
\hline Caption & $\begin{array}{l}\text { Can't face the world, yang berarti } \\
\text { 'tidak mampu menatap dunia' }\end{array}$ & $\begin{array}{l}\text { Khalayak sasaran tidak banyak } \\
\text { yang memaknainya, walaupun } \\
\text { ada yang dapat memaknai 'malu } \\
\text { untuk menampilkan dirinya' }\end{array}$ \\
\hline
\end{tabular}

yang sama) dengan ambient media. Pada ambient media boneka tertelungkup di Adorama Photo Kemang, pengunjung Adorama Photo sebagai khalayak sasaran dikondisikan melalui aktifitas mencetak foto di ruangan editing. Ruangan editing sebagai medan iklan menciptakan suasana yang menjadikan pengunjung penasaran melihat perilaku boneka perempuan yang tertelungkup.

Representasi naratif ambient media sebagai pelibat yang menempati ruang, membuka ruang dialog dengan khalayak sasaran sebagai pelibat. Kedekatan dalam satu layar ruang dan waktu ini memungkinkan pesan terbaca dan munculnya sebuah relasi. Pada Analisis praktek diskursus, menunjukkan bahwa ambient media sebagai media komunikasi telah banyak direspon khalayak sasarannya. Ambient media memiliki peran sebagai aktor dikarenakan penempatan media yang memiliki daya tarik dan mengambil ruang (space) pada medan di mana publik memasuki ruang. Lebih lanjut, ketika disadari bahwa model iklan terdiam - tidak layaknya manusia biasa - muncul relasi yang lebih kuat dengan ditunjukkan beberapa respon khalayak sasaran.

Caption: Can't face the world yang diletakan di dekat ambient media tidak banyak diperhatikan oleh publik pengunjung Adorama Photo maupun meja editing. Mereka cenderung tidak membaca pesan apalagi mengkaitkan dengan penyembunyian wajah ambient media yang berada di dekat mereka, namun ketika terdapat sebagian publik membaca caption yang diletakkan di dekat ambient media dan mampu menghubungkan keterkaitanya dengan representasi ambient media yang menenggelamkan wajah, maka makna mulai dibaca. Publik sadar bahwa ambient media sebagai subjek telah menguasai space dan waktu dengan khalayak sasaran, padahal subjek iklan hanyalah boneka perempuan. Kesadaran bahwa subjek yang menenggelamkan wajah hanyalah boneka, maka pengunjung mulai berani untuk memegang dan mengabadikan ambient media. Kembali para pria berperilaku 
menjadikan tubuh perempuan sebagai subordinat yang memungkinkan dipegang, disentuh atau lainnya.

Pilihan diksi caption: 'Can't face the world' memiliki arti "tidak dapat menatap dunia" yang dimaknai rasa malu yang dialami perempuan ketika wajahnya berjerawat. Caption ini tidak berhasil dibaca oleh sebagian pengunjung, apalagi dimaknai. Akan tetapi, sebagian khalayak memiliki pemaknaan yang berbeda dari makna yang dimaksud oleh pengiklan. Beberapa dari mereka memahaminya sebagai wanita yang mengantuk karena merasa capek setelah seharian bekerja sehingga membenamkan wajahnya ke meja. Tidak ada keterkaitan antara caption dengan ambient media.

Ambient media sebagai media praktek diskursus menunjukkan subjektivitasnya meng-giring khalayak sasaran untuk merespon, meskipun tidak memiliki pemaknaan yang sama dengan pengiklan.

\section{Praktek Sosial : Iklan Kecantikan sebagai Produk Kekuasaaan}

Narasi iklan ambient media Miracle Clinic sebagai bentuk iklan kecantikan memiliki latarbelakang wacana yang berusaha untuk mengkaitkan produk yang ditawarkan dengan sebuah konstruksi identitas diri; sebagai contoh dinarasikan sebagai subjek yang feminim di tengah sibuknya berkarir dan menjadi ibu rumah tangga; narasi sebagai perempuan yang harus berhadapan dengan debu jalanan dan ide narasi lainnya. Iklan kecantikan yang ditampilkan di setiap media menggiring pada ide kebenaran melalui alam bawah sadar bahwa secara kodrati perempuan harus tampil feminim. Khalayak sasaran diajak ke dalam suasana narasi pencitraan perempuan dengan berbagai aktifitasnya. Ketika khalayak iklan dipertontonkan dengan model iklan pen- cerah wajah, sehingga nampak wajah terlihat lebih putih, tanpa minyak, noda dan jerawat adalah nilai feminitas yang ditanamkan kepada konsumer bahwa representasi wajah tersebut sebagai indeks penampilan ideal wajah feminim. Representasi visual ini merupakan penuturan ulang pengetahuan wacana praktek sosial budaya yang terus disampaikan melalui teks visual: iklan.

Kecantikan wajah dan tubuh perempuan pada umumnya menjadi komoditas dalam membentuk wacana ideologi kecantikan. Konsep feminitas ideal adalah: tubuh langsing, kulit cerah berseri tanpa kerutan, rambut panjang lurus, dan dada besar, dilakukan secara ekspansif melalui berbagai macam bentuk iklan. Hasilnya tercipta anggapan benar dalam pikiran konsumer akan ideologi feminitas. Wacana feminitas ideal dibentuk oleh iklan sebagai pihak dominan yang men-subordinasi konsumer perempuan yang tidak memiliki kualitas feminitas.

Produsen kosmetik dan perusahaan pembuat iklan adalah pihak utama yang memiliki kepentingan pada wacana feminitas. Pihak-pihak tersebut selalu membentuk dan menyampaikan 'kebaruan wacana feminitas'. Pergeseran indeks kecantikan telah bergeser, baik potongan gaya rambut, warna gincu bibir, pengo-lahan rona pipi, dan permainan bulu mata. Tidak disadari, apapun pengolahan trend wajah tidaklah mungkin apabila kulit wajah tidak bersih oleh karena adanya jerawat. Ideologi wacana kecantikan bukan lagi bicara pada konteks mancung tidaknya hidung, tebal tipisnya bibir, namun bagaimana wajah tampil eksotis. Namun tetap dengan catatan wajah bersih tidak ada noda atau berjerawat.

Kekuasaan mengkonstruksi kecantikan tersebut terdapat konsep komersial di baliknya. Penjualan produk tidak dibatasi pada perempuan cantik saja tentunya, namun pada perempuan tidak cantik juga. Penetrasi ideo- 


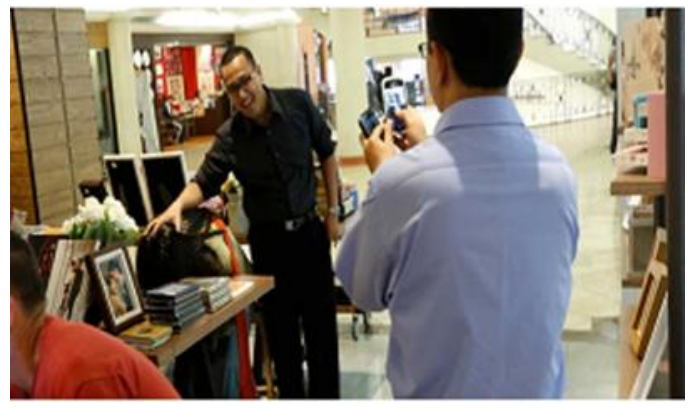

Gambar 3.

Respon Interaktif Pria terhadap Ambient Media tertelungkup.

Sumber: Wegig Murwonugroho, 2013

logi kecantikan ini melalui berbagai macam praktek mikro yang bersifat produktif dan diskursif. Foucault menjelaskan dominasi dan subordinasi yang dialami seseorang adalah hasil eksploitasi kekuasaan melalui berbagai macam praktek dari aksi suatu sumber kekuasaan yang tunggal. Wacana feminitas yang disematkan pada tubuh perempuan ditampilkan pada iklan bertujuan untuk mengkokohkan kuasa mengenai standarisasi kecantikan pada wajah dan tubuh perempuan.

\section{Praktek Sosial: Wacana Mitos}

Tanpa disadari oleh publik, seringkali di balik pesan iklan tersembunyi berbagai mitos sebagai representasi naratif. Iklaniklan produk kecantikan menguatkan mitos-mitos budaya dominasi ideologi feminitas ideal yang pada umunya dengan cara penampilan fisik yang menarik dan kemudaan pada wajah. Mitos sebagai sistem signifikasi, mengandung muatan ideologis yang berpihak kepada kepentingan mereka yang berkuasa (Kris Budiman, 1999:20). Perasaan malu menjadi sebuah keyakinan yang seringkali mempengaruhi di dalam kehidupan sosial. Mitos 'malu yang berlebihan' ketika wajah berjerawat ditanamkan menjadi sebuah budaya yang membatasi pergerakan perempuan tampil di ruang publik; tidak lagi menjadi komunitas perempuan yang berwajah bersih.

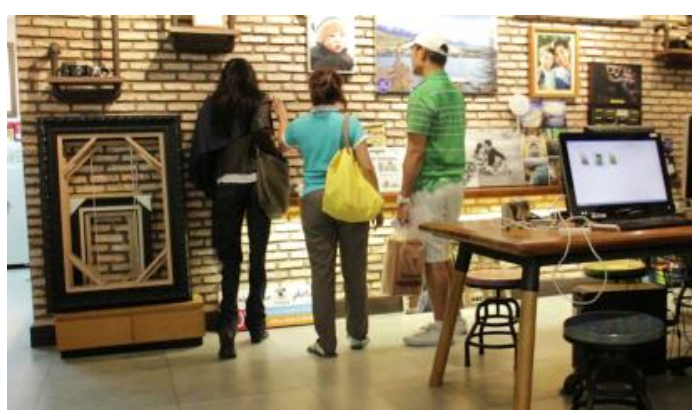

Gambar 4.

Respon Interaktif Wanita terhadap Ambient Media berdiri.

Sumber: Wegig Murwonugroho, 2013

Mitos mempengaruhi khalayak sasaran memaknai iklan. Mitos lahir dari pengalaman-pengalaman pribadi dan banyaknya 'wacana' yang diserap hingga terus tertanam hingga menjadi berakar sebagai kepribadian yang humanis hingga menjadi sebuah peristiwa traumatik. Dari focus group discussion yang dilakukan pada 25 pengunjung Adorama Photo Kemang diperoleh data beberapa wacana yang mempengaruhi respon sebagai bentuk Analisis praktek sosial.

Kebiasaan menonton serial film horor, maraknya poster iklan bioskop horor, buku cerita horor dan tayangan video horor yang ditayangkan di Youtube atau media sosial lain menyudutkan perempuan yang bergaya misterius sebagai perempuan yang menakutkan. Idealnya perempuan memiliki sifat feminim, keibuan, humanis, dan membawa aura ketenangan, kesejukan, dan sesuatu yang membahagiakan. Ketika representasi visual perempuan ditampilkan kontradiktif, maka mitos perempuan yang tidak lagi memiliki aura positif, munculah gambaran stereotype perempuan sebagai sosok yang menakutkan.

Persepsi pada kajian praktek sosial yang dominan melekat di benak khalayak sasaran adalah representasi hantu wanita tanpa muka. Makna sosial ini timbul karena adanya mitos mengenai perwujudan hantu 
Tabel 3: Wacana Sosial yang Mempengaruhi Pemaknaan dan Respon Interaktif Khalayak Sasaran

\begin{tabular}{|c|c|}
\hline Wacana yang Mempengaruhi & Pemaknaan dan Respon yang Muncul \\
\hline $\begin{array}{l}\text { Wacana mistis yang di } \\
\text { pertontonkan dalam film atau } \\
\text { poster, televisi, dan jejaring sosial }\end{array}$ & $\begin{array}{l}\text { - Ketakutan dan menjauhi model ambient media } \\
\text { - Tetap memasuki medan di mana ambient media ditempatkan, } \\
\text { mengamati, bertanya pelan-pelan kepada boneka. } \\
\text { - Tidak berani masuk ke toilet oleh karena ada asumsi ada } \\
\text { boneka perempuan lagi yang menakutkan. }\end{array}$ \\
\hline $\begin{array}{l}\text { Wacana humanis yang ditunjukkan } \\
\text { dengan narasi kepedulian atas } \\
\text { ketimpangan sosial dan moral }\end{array}$ & $\begin{array}{l}\text { Berani mendekati, muncul perasaan iba, bertanya keluh kesah } \\
\text { yang dihadapi boneka yang dikira perempuan nyata. }\end{array}$ \\
\hline $\begin{array}{l}\text { Wacana hiburan yang banyak } \\
\text { ditonton pada film lucu } \\
\text { Wacana media kreatif di dalam } \\
\text { iklan yang menjadi rutinitas } \\
\text { pekerjaan }\end{array}$ & $\begin{array}{l}\text { Lebih berani mengamati, coba bertanya, menyentuh hingga } \\
\text { merusak ambient media karena merasa tertipu. } \\
\text { Tetap tenang, mengamati subjek sebagai model iklan, dan } \\
\text { mencoba memahami pesan dan memaknainya. }\end{array}$ \\
\hline
\end{tabular}

perempuan di masyarakat Indonesia, dan mitos ini di-langgeng-kan oleh film ataupun sinetron horor. Representasi film horor yang sering menampilkan hantu wanita dengan penampilan rambut hitam panjang dan menyembunyikan muka. Pelibat memiliki persepsi bahwa ambient media yang mereka temui di meja editing merupakan penampakan hantu perempuan.

Ketika wajah model direpresentasivisualkan membelakangi audience, mitos mengenai perwujudan perempuan yang mengerikan; hantu, kuntilanak sundel bolong, suster ngesot menjadi wacana yang mempengaruhi persepsi pemaknaan iklan. Maraknya narasi horor yang dipertontonkan pada berbagai media hiburan (televisi, bioskop) dan jejaring sosial (Youtube) memunculkan kepercayaan yang berhubungan dengan metafisik. Muncul berbagai respon khalayak; tertegun, terkejut, takut hingga traumatik. Lebih lanjut muncul juga interaksi spontan yang dilakukan khalayak sasaran. Ada yang berharap model membalikkan wajah, meskipun sempat ketakutan apabila memiliki wajah rata atau berwajah seram. Khalayak mencoba memanggil, menyentuh, mengelus iba. Ambient media sebagai subjek telah mengkonstruksi suasana untuk mengajak dialog. Menantang respon khalayak untuk memilih sebagai subjek yang memiliki identitas humanis, humor atau malah terdiam.

Representasi visual ambient media yang dikonstruksi memiliki subjektivitas yang menjadikannya memiliki identitas dan kuasa untuk diperlakukan sebagai indi-

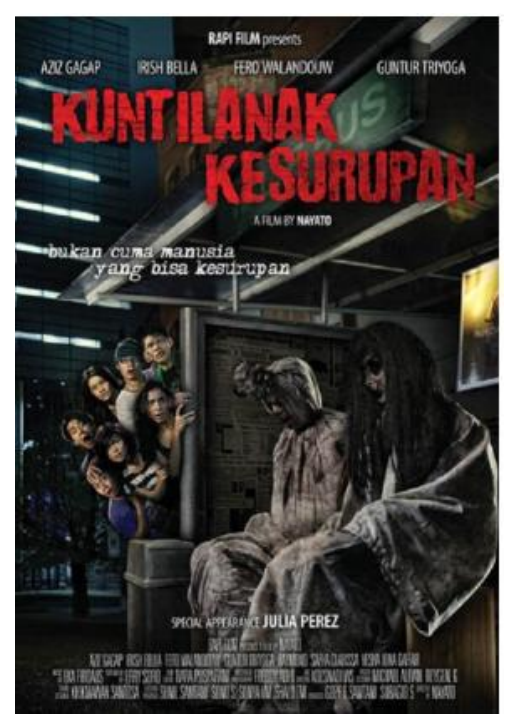

Gambar 5.

Representasi Visual Perempuan Menyeramkan dalam Poster Film

Kuntilanak, Sumber: http://

www.21cineplex.com/kuntilanakkesurupan-(kunt),2507.htm Diunduh 7 Januari 2014 
vidu. Akan tetapi publik tidak mendapatkan pesan bahwa ambient media adalah perwujudan iklan wanita yang menyembunyikan muka karena malu, wajahnya berjerawat. Ketakutan dan keterkejutan pengunjung Adorama Photo akan keberadaan ambient media bisa dipahami bahwa adanya kejanggalan, keunikan dan kreatifitas ambient media sebagai media yang memanfaatkan unsur-unsur lingkungan fisik.

Pada Analisis praktek sosial, mitos hantu perempuan menjadi wacana dominan yang mempengaruhi pemaknaan iklan. Subjektivitas iklan Miracle menyudutkan perempuan tidak dapat hadir di ruang publik, menjadi tersisih sebagai sosok yang mengerikan di dalam tataran sosialnya ketika wajah berjerawat.

\section{SIMPULAN}

Subjektivitas adalah suatu pengalaman, dan terbuka untuk ketidakkonsistenan, kontradiksi, dan kesadaran-bukan diri. Subjektivitas dibentuk oleh sistem dominan dari organisasi sosial yang bertujuan mengatur manusia. Ambient media dalam kajian Analisis tekstual teks telah menunjukkan identitasnya sebagai representasi visual tubuh perempuan. Tubuh boneka telah memanipulasi pan-dangan nyata (real) atau tidaknya model. Atribut yang disematkan pada boneka menunjukkan identitas sosial subjek. Penyembunyian wajah mengkonstruksi subjektivitas di mana perempuan sebagai subjek yang tidak terbatas pada makna tertunduk malu, sedih, dan perasaan emosional lainnya. Akan tetapi sebagai bentuk representasi hilangnya identitas jender perempuan karena wajahnya yang berjerawat tidak memenuhi syarat feminitas ideal. Kemunculan polisemi pemaknaan ambient media sebagai sebuah teks dipenga- ruhi oleh adanya latar belakang pengetahuan dan pengalaman di dalam memaknai tanda.

Di dalam konteks praktek diskursus, pemilihan medan ruang editing Adorama Photo Kemang di mana ambient media ditempatkan mempengaruhi kedudukan setiap pelibat di dalam memainkan perannya. Terlihat iklan memiliki kuasa sebagai aktor untuk menyampaikan pesan. Khalayak sasaran yang hadir dalam keterbatasan ruang dan waktu yang sama juga dipaksa memainkan perannya untuk merespon iklan. Berbagai respon khalayak sebagai pelibat bermunculan; sebagian pelibat terdiam ketakutan, namun ada juga yang mendekat, membaca, menyentuh, dan memegang sebagai bentuk relasi antar pelibat. Dengan demikian terjadi dialog antara iklan dengan khalayak sasarannya dalam konteks praktek diskursus. Ambient media menunjukkan subjektivitas-nya menggiring khalayak sasaran untuk merespon.

Ketika terjadi interaksi sosial, muncul wacana-wacana sosial; wacana mitos hantu perempuan menjadi wacana yang mendominasi pemaknaan iklan. Subjektivitas iklan Miracle yang menyudutkan perempuan yang berjerawat identik dengan wajah yang menyeramkan. Dari narasi ini menyadarkan perempuan untuk senantiasa mengkonsumsi obat perawatan wajah agar wajah terlihat bersih. Miracle cukup berhasil mengkonstruksi wacana trend baru kecantikan wajah tidak terbatas pada tolok ukur karakteristik kecantikan pada umumnya, namun ada kebaruan ideologi kecantikan yang dapat dihadirkan dengan wajah yang bersih. Kehadiran ambient media Miracle sendiri juga memunculkan wacana ideologi kecantikan dan wacana baru di dalam beriklan sebagai kontribusi dalam periklanan Indonesia. 


\section{Daftar Pustaka}

\section{Evi Fadillawati}

2011 Subjektivitas dan Identitas Kebudayaan Indonesia: Fast-Food sebagai Identitas Baru di Kalangan Kaum Muda. Jakarta: Fakultas Ilmu Sosial UNJ.

Fitryarini

2009 "Iklan dan Budaya Popular: Pembentukan Identitas Ideologis Kecantikan Perempuan oleh Iklan di Televisi". Jurnal Budaya.

Genz, Stephanie

2009 Post Feminism in Popular Culture. United Kingdom: Palgrave Macmillan.

Giles, Judi \& Middleton, Tim

2008 Studying Culture: A practical Introduction, 2nd Edition. New Jersey: Wiley-Blackwell.

Graeme, Turner

2003 British Cultural Studies: An Introduction (3rd Ed). New York: Routledge.

Kris Budiman

1999 Feminografi. Yogyakarta: Pustaka Pelajar.
Mansfield, Nick

2000 Subjectivity: Theories of the self from Freud to Haraway. Australia: National Library of Australia.

Mark, Kelly, G.E.

2000 Subjectivity, and Technologies of the Self. Academia.

McLaren, Margaret A.

2002 Feminism, Foucault, and Embodied Subjectivity. (s.i) : (s.n)

Paramita Ayuningtyas

2009 Identitas Diri yang Dinamis: Analisis Identitas Gender dalam Novel Breakfast on Pluto Karya Patrick Mc.Cabe. Jakarta: FIB UI.

Rizma Afian Azhiim

2014 Identitas Dan Subjektivitas Budaya Populer Cosplay di Indonesia. Universitas Al Azhar Indonesia, International Relations. 